\title{
EDUCAÇÃO POPULAR E EMPODERAMENTO: A PALAVRA COMO EXERCÍCIO DO SABER COLETIVO
}

\author{
Raquel Célia Silva de Vasconcelos ${ }^{1}$
}

\begin{abstract}
Resumo
Este artigo tem como objetivo analisar a palavra como exercício do saber coletivo no empoderamento da educação popular. Para a educação popular a palavra é o exercício do saber coletivo. O poder é exercido a partir da autoridade que se apresenta como espaço da participação da coletividade. A participação corresponde aos acontecimentos que contribuem para o crescimento de um grupo identitário. $\mathrm{O}$ acesso à educação pública de qualidade pressupõe a participação popular no espaço escolar via de regra corresponde a efetivação do espaço coletivo para identificação dos elementos culturais em direção ao processo de humanização.
\end{abstract}

Palavras-chave: Espaço coletivo. Educação de qualidade. Processo de humanização.

\section{POPULAR EDUCATION AND EMPOWERMENT: THE WORD AS AN EXERCISE OF COLLECTIVE KNOWLEDGE}

\begin{abstract}
This article aims to analyse the word as an exercise of collective knowledge in the empowerment of popular education. For popular education, the word is the exercise of collective knowledge. Power is exercised from the authority that presents itself as a space for collective participation. Participation corresponds to events that contribute to the growth of an identity group. Access to quality public education presupposes popular participation in the school space and, as a rule, corresponds to the realisation of the collective space to identify cultural elements towards the humanisation process.
\end{abstract}

Keywords: Collective space. Quality education. Humanisation process.

\section{Introdução}

A educação como via direta de acesso ao capital cultural corresponde ao acesso direto aos benefícios materiais e simbólicos que a escola deveria garantir, uma vez que na escola estaria a possibilidade de transformação da estrutura que visa a educação apenas como oportunidade

1 Licenciatura e Mestrado em Filosofia, Especialista em Psicopedagogia Clínica e Institucional, e graduanda no curso de Licenciatura em Pedagogia pela Universidade Estadual do Ceará. Doutora em Educação e Especialista em Educação Especial - Formação Continuada de Professores para o Atendimento à Educação Especializado - AEE pela Universidade Federal do Ceará. Desenvolve atividades no campo das Artes - Cinema de Animação, Artes Plásticas (Pintura, objetos e escultura) e Fotografia. Professora do Curso de Pedagogia da Uninassau - Ser Educacional. Professora Formadora no Centro de Educação da Universidade Estadual do Ceará/UAB, no núcleo de Educação a Distância, no curso de Licenciatura em Pedagogia. Professora colaboradora no Mestrado em Ciências da Educação - Faculdade Cecap. ORCID: https:// orcid.org/ 0000-0001-6006-431. E-mail: raquelcsvasconcelos@gmail.com. 
àqueles que se definem como os únicos capazes e privilegiados de estarem no espaço escolar. Embora sabemos que a educação diz respeito ao domínio de ideias e práticas atravessadas pelas diferenças que envolvem inúmeras realidades sociais.

A educação popular se situa num complexo de situações que a fez emergir na história da humanidade. Seus contextos se diferem de acordo como a educação é apropriada, pensada e praticada por quem a determinou, podendo ser libertadora ou opressora. A educação popular reivindica uma educação para a libertação de todas as formas de opressão.

Nessa perspectiva, este artigo está atravessado por três momentos: o primeiro, "A desobediência através do uso da palavra beneficiando o espaço coletivo", o segundo, "Estado e direito à educação de qualidade: avanços e retrocessos na institucionalização do ensino público”, e o terceiro, "A educação e a identificação dos elementos culturais como processo de humanização".

\section{A desobediência através do uso da palavra beneficiando o espaço coletivo}

A educação popular tem no poder da palavra o pressuposto para o exercício do saber coletivo. Nesse exercício a autoridade se apresenta como espaço da participação coletiva através do relato dos acontecimentos que contribuem para o crescimento de um grupo identitário. A autoridade pertence ao grupo cujos integrantes exercem o "direito de falar e ser ouvido" (BRANDÃO, 1986, p. 7), diferentemente da sociedade patriarcal cuja prática autoritária está no chefe que detinha "a posse do direito de pronunciar o sentido do mundo e, por isso, o direito de ditar a ordem do mundo social. Ele é quem transformou um dever coletivo e anterior de dizer, no poder de ditar e ser, assim, obedecido; [...]" (Ibidem).

Nesse aspecto, o ato de obediência imposta aos demais integrantes do grupo delineia um processo de marginalização "do lugar onde se fala aquilo que transforma o mundo" (Ibidem). Com isso, o chefe delimita a relação entre justiça e o poder da palavra, bem como sua legitimação porque nem sempre a fala do justo é justamente a palavra necessária e nada garante que essa fala seja legítima.

Portanto, o direito de falar e ser ouvido atravessa o ato de educar porque é preciso que a legitimação da palavra, ao se apresentar como verdadeira, permitam enunciados válidos que não

\begin{tabular}{|c|c|c|c|}
\hline Qevista Dialectus & Ano 10 & n. 24 & Setembro - Dezembro 2021 \\
\hline
\end{tabular}


fiquem restritos ao conhecimento científico, ou a verdade da ciência, mas também aos saberes enunciados que não passem pelo crivo do more geometrico cuja legitimação resulta apenas da racionalidade científica.

Como assinala Foucault (1979) quando afirma que vivenciamos, referindo-se ao período da década de 60 do século XX, uma descontinuidade histórica uma vez que "não se trata de saber qual é o poder que age do exterior sobre a ciência, mas que efeitos de poder circulam entre os enunciados científicos; qual é seu regime interior de poder; como e por que em certos momentos ele se modifica de forma global" (FOUCAULT, 1979, p. 6), a ponto de assumir constantes processos de legitimação dos enunciados.

Foucault desconfia de qualquer tentativa de consenso porque este parte de uma legitimação discursiva suprema suprimindo os demais discursos, trata-se de um discurso de verdade impositivo. Qualquer aproximação, portanto, entre Foucault e Lyotard provavelmente esteja atravessado pela tentativa de ambos em uma desconstrução dos discursos de verdade uniformizadores a partir de enunciados, anuncia Lyotard em "A condição pós-moderna", que atravessa uma sociedade do dissenso. A presença desta, afirma Lyotard, sinaliza o fim das metanarrativas dos enunciados totalizantes, portanto, o fim da legitimação dos mesmos. Nessa perspectiva, Foucault pensa em enunciados discursivos das diferenças, das "verdades" e do lugar de fala.

Para Lyotard vivenciamos, referindo-se também à década de 60 do século $\mathrm{XX}$, o dissenso discursivo porque a experiência pós-moderna decorre da perda de nossas crenças em visões totalizantes da história, que prescrevem regras de conduta política e ética para toda a humanidade, resultante de uma visão de progresso científico a partir do império da razão. Um império que determina as ações dos indivíduos a partir de uma divisão social do poder que se realiza

entre os homens como oposições simbólicas — e nem por isso menos reais — de diferenças do poder de falar. Palavras que ordenam a vontade de poucos sobre o trabalho de muitos, são as que criam os nomes de todas as coisas na sociedade onde o poder existe separado do trabalho produtivo, tanto quanto da vida simbólica coletiva. Mundos sociais onde o ofício de pronunciar a palavra necessária distancia-se do consenso; do pensá-la em comum como poesia e pensamento da vida coletiva sem a desigualdade, e da experiência da solidariedade através das diferenças. Aprisionada por um poder separado da vida, a palavra sem o consenso torna-se a fala necessária para a sociedade e, por isso, é imposta e dada como legítima para realizar os atos do controle da vida social dominada pela

n. 24

Setembro - Dezembro 2021

p. $233-247$ 
desigualdade. (BRANDÃO, 1986, p. 8, crivo do autor).

Trata-se de uma crítica, tanto de Brandão como de Foucault, ao processo de normalização da vida a partir do ordenamento e da verdade da norma, que "dita e principalmente escrita é como o selo, mais do que o sinal, de um poder desde onde a posse não contestada do direito de dizer o sentido de tudo, de torná-lo legítimo e fazê-lo circular como saber crença, idéia, valor e código, [...] do seu exercício sobre o silêncio do outro" (Ibidem).

A legitimação do poder corresponde ao seu pronunciamento em palavras ordenativas, sobretudo com o aparecimento da escrita via contabilização dos bens dos senhores, tornando possível sua extensão. O aparecimento da escrita converge com determinados traços de comportamento e conduta da civilização expressos nas cidades e nos impérios com seus sistemas políticos hierarquizados, uma escrita cuja função é impor uma espécie de servidão voluntária. A escrita trouxe práticas até então ausente nos grupos sociais de predominância da palavra oral.

\footnotetext{
Apenas a palavra oral primitiva, a palavra em estado de ser popular, possui em si mesma a sua densidade plena e, portanto, diz em si mesma e, não, para alguma coisa. Ao falar do sentido do "dizer a palavra" entre os índios Guaiaqui, do Paraguai — até hoje pequenos bandos errantes de caçadores - Pierre Clastres recorda que "entre grupos sociais sem poder de estado e sem a sua conseqüente palavra escrita, o que se fala possui a densidade do poema, porque a palavra oral é mais celebrada como um rito que conduz a possibilidade da comunicação, do que usada como o dito (a ordem, o édito, o edital) que constitui a imposição (PIERRE CLASTRES, “A Sociedade contra o Estado", p.88 apud BRANDÃO, 1986, p. 9).
}

O poder e a palavra na sociedade tribal corresponderia ao consenso solidário que reconheceria os conflitos, mas não se trata de um consenso oriundo de uma sociedade sem a presença do Estado, cuja prática atravessa o exercício da palavra como um direito do poder. $\mathrm{Na}$ sociedade tribal o poder, a palavra e a relação entre eles corresponderia ao dever do poder, isto significa que "aquele a quem a tribo designa ser o chefe tem a obrigação de ser digno de pronunciar palavras através das quais todos pensam; através das quais todos compreendem a verdade do mundo - e isto são mitos, crenças e cantos - e a norma da vida - e isto são valores, regras e códigos" (BRANDÃO, 1986, p. 10).

A fala do chefe corresponde à vontade coletiva porque ele enuncia o conhecido e o consagrado resultantes de um poder, cujo lugar social comunga uma fala inscrita no seu lugar do poder. Nesse aspecto, não há desigualdade nos diferentes enunciados pronunciados, na verdade

\begin{tabular}{|l|l|l|l|l|}
\hline Qevista Dialactus & Ano 10 & n. 24 & Setembro - Dezembro 2021 & p. $233-247$ \\
\hline
\end{tabular}


eles ecoam a partir da vontade na fala de todos e todas.

Nessa perspectiva, a educação como foi constituída no Brasil precisa ser repensada quando se pensa sobre a educação popular que se encontra sobre "um domínio de idéias e práticas regido pela diferença" (Idem, p. 12). Por isso, Brandão (1986) propõe "quatro diferentes sentidos da educação popular: 1) como a educação da comunidade primitiva anterior à divisão social do saber; 2) como a educação do ensino público; 3) como educação das classes populares; 4) como a educação da sociedade igualitária" (Idem, p. 13).

Assim, a educação popular deve ser vista como um processo geral do saber da comunidade que surge e circula conforme o aperfeiçoamento da capacidade humana de produção cultural resultante do conhecimento simbólico.

\begin{abstract}
Desprotegidos de força e armas do corpo para matar ou fugir e, inicialmente, desprovidos de um saber necessário que pudesse passar de um corpo a outros, os pequenos seres humanos atravessaram longos períodos da vida convivendo em companhia de iguais no interior de grupos cada vez mais estáveis e, ao longo do tempo, cada vez mais complexos: bandos errantes, hordas, famílias, parentelas, clãs, aldeias, tribos, onde por sobre as tarefas de reprodução da vida física, os homens aprender a criar a vida simbólica. A criar um tipo absolutamente novo de trocas onde entre um ser e outro não há apenas eles e a natureza, mas também objetos - o produto do trabalho do homem sobre a natureza - sinais, símbolos, instituições e significados - o produto do homem sobre si mesmo - a cultura. (BRANDÃO, 1986, p. 17).
\end{abstract}

A cultura como produção do conhecimento simbólico significa a ação do homo sapiens sapiens, responsável pela reprodução da vida individual e coletiva a partir da convivência estável e da comunicação. Conforme Brandão (1986) a produção simbólica do homo sapiens sapiens expressa o primeiro sentido de educação e educação popular por designar um modo social de convivência como aprendizado coletivo mediado pelos ritos.

Assim, a divisão social do saber após o aparecimento da cidade fez com que "um saber da comunidade torna-se o saber das frações (classes, grupos, povos, tribos) subalternas da sociedade desigual. [...], através das quais o saber das classes populares ou das comunidades sem classes é transferido entre grupos ou pessoas, são a sua educação popular" (Idem, p. 26, grifo do autor). Há, ao longo da histórica humana, uma violência simbólica das especialidades eruditas sobre a produção cultural popular, um exemplo disso perpassa a supervalorização das especialidades da ciência a partir da negação e/ou anulação do conhecimento popular e da 
concepção de sagrado que não se inscreva nas religiões colonizadoras.

Nesse sentido, a educação popular não pode ser limitada a um trabalho de democratização do saber escolar atravessado por um ensino delineado pelo discurso de uma educação laica e pública, mas como lugar de fala e reconhecimento de saberes que estão para além do espaço escolar, saberes esses que, de modo direto ou indireto, também contribuem à proposta de uma educação popular.

\section{Estado e direito à educação de qualidade: avanços e retrocessos na institucionalização do ensino público}

Se pensarmos a proposta do Relatório Delors, que delineia o discurso "Educação para Todos", o acesso à escola, a permanência e o respeito aos saberes extra-curriculares depende da forma como compreendemos as diferenças na educação.

[...] quando as oportunidades de chegar à escola, de permanecer nela o tempo devido e de obter, do que ali se troca, todos os bens da educação, estão desigualmente distribuídas, isto se deve a problemas como os seguintes: 1) as disponibilidades econômicas do país, ou de algumas regiões, não permitem investimentos suficientes para que todos recebam toda a educação devida, por enquanto; 2) outros problemas que não os "de educação" impedem ou dificultam a presença regular de crianças pobres ou "de meio rural" na escola; 3 ) famílias com uma história crônica de baixos índices de escolaridade, de dificuldades de trabalho e, conseqüentemente, de carências de nutrição, saúde e estabilidade, não possuem um interesse persistente pela educação de seus filhos. (BRANDÃO, 1986, p. 33).

Diferenças que expressam uma exclusão social resultante da divisão, como assinala Brandão (1986), entre o trabalho e o poder que o sistema de educação escolar reproduz paralelamente ao desenvolvimento da capacidade simbólica, negando qualquer possibilidade histórica de transformação social, sobretudo porque, "na prática, a educação escolar não é oferecida a todos da mesma maneira e, assim, dos bancos e das salas de aula dos seus vários "níveis" ou "graus", saiam desigualmente repartidos para a vida e o trabalho." (Idem, p. 34).

$\mathrm{Na}$ verdade, as instituições controladoras e definidoras do paradigma educacional para o século XXI facilitam a desigualdade quando a oferta dos bens da escola não se torna privilégio às nações mais pobres, eles não têm os mesmos bens escolares que países centrais da ordem capitalista (os mais ricos e desenvolvidos) possuem, a diferença do capital cultural entre as nações pobres e as ricas é abissal. 
A superação dessa diferença abissal parece ser impossível, como assinala Bourdieu, porque a conversão do capital econômico em capital cultural corresponde ao investimento escolar apresentado como benefícios materiais e simbólicos. Estas são garantias resultantes da certificação escolar oriundas das estratégias de reconversão do capital econômico em capital escolar permitido pela explosão de escola e a inflação de diplomas, resultantes "das transformações da estrutura das oportunidades de lucro asseguradas pelas diferentes espécies de capital.” (BOURDIEU, 2015, p. 88) Esse capital cultural não alcança e nem se aproxima do saber popular, este se constitui no campo coletivo, aquele é forjado no âmbito individual apartado da participação de um saber compartilhado.

Isso pressupõe o quanto é complexo delimitar ou definir o que corresponde ensino escolar do povo, sobretudo porque a luta por uma educação popular no Brasil sempre fora pensada por pessoas que não são pertencentes à população que expressam desejos coletivos. Todas as

pessoas do povo, nossos índios, negros e brancos pobres, ausentes do trabalho coletivo de fazer a história, a não ser quando servem" aos interesses de uma elite, líderes do povo como 'Zumbi ou Antônio Conselheiro, são massas anônimas de 'gentes', tribos e grupos. Mas são plenos sujeitos 'da cultura'. Então os livros povoam o território que o senhor e seus emissários conquistaram de incontáveis 'tipos culturais' que foram povoando: gaúchos, caipiras, capoeiras, baianas, seringueiros, nordestinos” (BRANDÃO, 1986, p. 40 crivo do autor).

Pesquisas apontam que a presença dos movimentos sociais nas lutas e conquistas da educação sempre foram uma bandeira de luta dos pobres do campo e da cidade, produtores anônimos de culturas, eles sempre estiveram interessados pela educação dos seus filhos. De certa forma, a invisibilidade imposta à prática de uma educação popular existente tem sua razão de ser para que ela permanecesse "fora do âmbito da escola, da educação seriada. Fora também e, para alguns, fora principalmente dos espaços e sistemas oficiais da educação escolar. Por isso, durante algum tempo houve um esforço para associar a educação popular a um modo alternativo de trabalhar com o povo através da educação" (Idem, p. 42). Então a efetivação da educação popular se torna possível porque

ao mesmo tempo que é necessária e legítima a ampliação de experiências autônomas e alternativas de uma educação popular realizada entre movimentos populares, movimentos sociais e agências civis de educadores participantes, é também importante a redefinição da educação pública de modo a que, à custa de

\begin{tabular}{|c|c|c|c|c|}
\hline Rovita Dialectus & Ano 10 & n. 24 & Setembro - Dezembro 2021 & p. $233-247$ \\
\hline
\end{tabular}




\begin{abstract}
lutas e conquistas, ela venha a se transformar em uma educação oferecida, pelo poder de Estado, a serviço de interesses e projetos das classes populares. Isto é parte do projeto histórico de um dia toda a educação realizar-se, em uma sociedade plenamente democrática, como uma educação popular. (BRANDÃO, 1986, p. 43).
\end{abstract}

Tendo como norte a afirmação acima, pode-se cogitar que o trabalho de libertação por meio da educação popular pressupõe que ela deva ser vista como educação das classes populares porque se realiza a partir do "trabalho coletivo em si mesmo, [...], é o momento em que a vivência do saber compartido cria a experiência do poder compartilhado" (Idem, p. 72).

\begin{abstract}
Em outras palavras, as práticas da educação popular representam desde já a vontade de criar espaços autônomos, espaços nos quais o manejo do poder se realize em forma compartilhada, dentro de uma crescente relação entre iguais. Nesta perspectiva as opções metodológicas adquirem relevância especial... A busca de formas educativas de caráter participativo, de reflexão coletiva da prática dos próprios atores, do desenvolvimento de relações de solidariedade entre os membros, a superação dos dogmatismos e preconceitos etc., constituem opçõeschave neste sentido." (La Educación Popular Hoy en Chile: Elementos para Definir, p. 13 apud BRANDÃO, 1986. P. 72).
\end{abstract}

A educação popular corresponde a uma prática regida pela diferença cujo sentido é o

"fortalecimento do poder popular, através da construção de um saber de classe" que se realiza na "vivência da educação popular" (Idem, p. 73). Por isso, ela é o movimento da prática pedagógica dirigida ao povo como um instrumento de conscientização, prática essa que converge com a relação entre educadores e movimentos populares para a ação política, ou seja, a educação popular é um ato político.

A educação popular desvela que a democracia delineia uma relação de dominação econômica e política dos donos do capital sobre a classe trabalhadora a partir da estrutura econômica, cuja base permeia a relação assalariada de produção imposta pela burguesia mediada pela regulação da sociedade via um modus vivendi delimitada por "regras, normas, formas de conduta, valores, ideias, as quais são reproduzidas e controladas por meio das instituições políticas, jurídicas e militares que compõem o Estado burguês.” (ARAÚJO, 2016, p. 322).

Nesse sentido, o Estado assume sua função ideológica que reproduz e representa a ideologia dominante, seu exercício de controle se dá a partir do "exército permanente e a política são os principais instrumentos do poder governamental”. (LÊNIN, 2005, p. 31 apud ARAÚJO, 2016, p. 322) Nesse contexto a escola assume suas duas principais funções de caráter classista:

\begin{tabular}{|l|l|l|l|l|}
\hline Qevista Dialectus & Ano 10 & n. 24 & Setembro - Dezembro 2021 & p. 233 - 247 \\
\hline
\end{tabular}


uma delas seria a de preparação da mão de obra para atender ao mercado e a de reprodução da ideologia dominante.

Por conseguinte, a institucionalização da educação (burguesa) diz respeito à “expansão do sistema do capital, como também gerar e transmitir um quadro de valores que legitima os interesses dominantes." (MÉSZÁROS, 2005, p. 35 apud ARAÚJO, 2016, p. 323) A universalização da escola na sociedade capitalista se mostrou sempre dicotômica desde sua origem, presenciando-se duas escolas: aquela que forma as elites dirigentes do sistema e uma outra direcionada ao "ensino básico-profissionalizante para os trabalhadores" (ARAÚJO, 2016, p. 324).

Por certo, os rumos tomados pela política educacional brasileira transformam a escola em um instrumento a seu serviço na reprodução das relações sociais de produção, eles trazem a falácia da escola como o lugar de formação do cidadão. Para isso, o Estado, a partir do Plano Nacional de Educação, deveria identificar desafios e possibilidades para a construção de condições de concretização de uma educação pública pautada na necessidade de corrigir o déficit educacional historicamente acumulado.

Nesse sentido, quem planeja a Educação é o Estado com o intuito de "implantar uma determinada política educacional com a finalidade de levar o sistema educacional a cumprir as funções que lhe são atribuídas enquanto instrumento deste mesmo Estado”. (HORTA, 1985, p. 195 apud ARAÚJO; AYRES, 2016, p. 02) O Estado, na condição de regulador da sociedade, estabelece os mecanismos de controle social através da escola ao fazer intervenções na educação por intermédio “do planejamento, da política e da legislação educacional” (ARAÚJO, 2016, p. 325).

Assim, o Estado através do planejamento visa "[...] implantação de um determinada política educacional do Estado, estabelecida com a finalidade de levar o sistema educacional a cumprir as funções que lhe são atribuídas enquanto instrumento deste mesmo Estado." (HORTA, 1985, p. 195 apud ARAÚJO, 2016, p. 325).

\section{A educação e a identificação dos elementos culturais como processo de humanização}

O Estado, para a manutenção do controle da sociedade através da escola, usou diversos mecanismos, como a efetivação do currículo no espaço escolar, a formação de professores, a avaliação entre outras de permanência do seu caráter normativo e centralizador, sobretudo no

\begin{tabular}{|l|l|l|l|l|}
\hline Qonista Dialectus & Ano 10 & n. 24 & Setembro - Dezembro 2021 & p. 233 - 247 \\
\hline
\end{tabular}


advento do Neoliberalismo uma vez que "[...] a política educacional [...] norteada por dois eixos centrais: a centralização e a descentralização [...]" (ARCE, 2001, p. 258-259 apud ARAÚJO, 2016, p. 325) delimita as ações do Estado nos mecanismos de controle social.

Vale ressaltar que é preciso reconhecer os limites do sistema educacional quando assume sua função reprodutora, mas não se pode negar por completo a importância da escola como agente transformador uma vez que a educação conduz à emancipação humana ao assumir concomitantemente sua competência técnica e seu compromisso político. Portanto, é preciso demarcar os limites e as possibilidades da escola enquanto espaço de atuação política de quem lida com a educação.

[...] o trabalho educativo é o ato de produzir, direta e intencionalmente, em cada indivíduo singular, a humanidade que é produzida histórica e coletivamente pelo conjunto de homens. Assim, o objeto da educação diz respeito, de um lado, à identificação dos elementos culturais que precisam ser assimilados pelos indivíduos da espécie humana para que eles se tornem humanos e, de outro lado e concomitantemente, à descoberta das formas mais adequadas para atingir esse objetivo. (SAVIANI, 2003, p.13 apud Araújo, 2016, p. 329-330).

Nessa perspectiva, fica sob a responsabilidade dos docentes esse processo emancipatório e, para isso, é necessário que o docente produza no educando sua humanidade, uma tarefa nada fácil porque seu desenvolvimento parte de uma formação unilateral e mutilada. $\mathrm{O}$ docente precisa compreender que na demonstração da realidade e do poder aos discentes não está na dimensão da representação, mas da práxis como condição de desvelamento da exploração do trabalho, inclusive de sua força de trabalho pelo Estado.

Vale ressaltar que Marx concebe a práxis como uma atividade humana de dimensão prático-crítica. Ela nasce da relação homem-natureza, pois a natureza só adquire sentido à medida que ele a modifica para satisfazê-lo. É a práxis que conduz o educador à luta política, pois somente a educação para a luta política permite ao profissional da educação educar e reeducar a si mesmo.

Portanto, trata-se de uma educação que não está restrita aos muros da escola uma vez que ela deve vir dos condicionamentos sociais a partir da ação determinante porque "no interior das escolas e das universidades em prol da educação pública e gratuita em todos os níveis”, a partir do "estabelecimento de uma escola única e de formação omnilateral, [...], a luta pela superação da ordem capitalista e pela conquista da emancipação plena, constituem tarefas do conjunto dos trabalhadores organizados como classe para exercer seu papel revolucionário na história." 
(ARAÚJO, 2016, p. 332-333).

Assim, o Estado planeja a educação por meio de seus órgãos específicos com a finalidade de implantar uma política educacional que atenda aos seus interesses e de uma elite que determinam as políticas educacionais para atender aos interesses do capital. Isto revela a ausência de neutralidade por parte do Estado e sua intencionalidade simultaneamente revelada e velada.

Na verdade, a reforma da educação, em um contexto de crise política e econômica, impõe uma profissionalização precoce aos jovens estudantes do ensino médio ao tornar obrigatórias apenas português e matemática e a 'formação técnica e profissional' como recurso de escolarização apressada para a formação de mão-de-obra e reprodução da ideologia dominante, afastando-os da formação acadêmica e das disciplinas das humanidades que permitiriam o pensamento crítico-reflexivo.

Assim, as decisões tomadas em Jomtien direcionam, como assinalam Araújo e Ayres, os documentos e campanhas para a reforma educacional, inclusive no campo da gestão que, por sua vez, adota os procedimentos que os países devem seguir para atender a Carta de Jomtien, cujas metas seriam a promoção de políticas de apoio econômico, social e cultural; e na mobilização de recursos financeiros, públicos, privados e voluntários. São metas que convergem com as reformas propostas pela Comissão Econômica para a América Latina e Caribe (CEPAL) presente no documento Educacion y conocimento: eje de la trasnformación productiva con equidade (1992).

O documento, [...], enfatizava a necessidade de reformas administrativas que operassem uma transmutação do Estado administrador e provedor para um Estado avaliador, incentivador e gerador de políticas. Para tanto, recomendava que se conjugassem esforços de descentralização e de integração, o que pode ser traduzido em desconcentração de tarefas e concentração de decisões estratégicas. A urgência na implantação de uma reforma educacional marcada pelas estratégias recomendadas pela CEPAL, em 1992, foi marcadamente reiterada por outros organismos multilaterais ao longo da década. (SHIROMA, MORAES E EVANGELISTA, 2000, p. 65).

As discussões supracitadas apontam que os diferentes tipos de planejamentos estão situados em contextos históricos específicos e corresponde a uma determinada conjuntura econômica, social e política. Isto pressupõe a elaboração de uma nova lei que traga as bases para a educação capaz de atender aos acordos internacionais articulados pela CEPAL, no Brasil, temos a Lei de Diretrizes e Bases da Educação Nacional - LDB 9.394/96.

Para a elaboração da referida Lei ocorreu todo um planejamento da educação que a

\begin{tabular}{|l|l|l|l|l|}
\hline Qovista Dialactus & Ano 10 & n. 24 & Setembro - Dezembro 2021 & p. 233 - 247 \\
\hline
\end{tabular}


LDB deveria atender. Na referida Lei são identificados "um processo de centralização na elaboração e na avaliação da política educacional, um processo de descentralização na sua execução". (ARAÚJO; AYRES, p. 6) Nela, conforme o Art. 11, os municípios terão como responsabilidade a "organização, manutenção e desenvolvimento dos órgãos e instituições oficiais de seus sistemas de ensino, integrando-os às políticas e aos planos educacionais da União e dos Estados".

O Plano Nacional da Educação (PNE), previsto na LDB, é o plano global e o exemplo do controle direto do Estado a partir de metas e estratégias cujos objetivos seriam alcançar todos os níveis e modalidades de ensino em direção à cidadania. O PNE se constitui "um plano de Estado porque 'perpassa vários governos, os quais devem/deveriam elaborar seus planos de governos, isto é, planos de gestão, guardando fina sintonia com este'." (ARAÚJO; FARIAS; SOBRAL, 2013, p. 2 apud ARAÚJO; AYRES, 2016, p. 7, crivo das autoras) É fato que o PNE corresponde a "principal medida de política educacional decorrente da LDB”. (SAVIANE, 1998 apud ARAÚJO; AYRES, 2016, p. 8).

Na lógica neoliberal o conceito de cidadania corresponde ao processo de privatização dos direitos sociais que somente terá acesso a esses direitos os indivíduos produtivos por terem condições de poder de compra. Isto delimita que "o modelo do homem neoliberal é o cidadão privatizado, responsável, dinâmico: o consumidor." (GENTILI, 2014, p. 21) Nessa lógica tudo é privatizado, sobretudo o sucesso e o insucesso individual e social.

O novo indivíduo incorpora um valor correspondente ao seu poder de compra, na dimensão educativa, ele passa a ser pensado "como 'capital humano' individual, deve ser um assunto que compete pura e exclusivamente à esfera das decisões e escolhas privadas que cada um precisa assumir, com o objetivo de melhorar sua posição relativa nos mercados." (Idem, p. 21-22).

Para tal feitio, o Estado seria "inoperante e faz o indivíduo irresponsável e incompetente uma das causas mais evidentes da crise da escola." (Idem, p. 22) Somente a iniciativa privada seria capaz de produzir o modelo de homem neoliberal, são nas grandes corporações que se encontram os 'experts' porque o sucesso de uma grande empresa pressupõe um "excelente gestor", justamente o que falta na escola: a tutela de um administrador gerenciando a educação, nesse discurso está nítido que o Estado não tem competência para conduzir as escolas ao mercado competitivo.

\begin{tabular}{|c|c|c|c|c|}
\hline Qevista Dialectus & Ano 10 & n. 24 & Setembro - Dezembro 2021 & p. $233-247$ \\
\hline
\end{tabular}


O raciocínio neoliberal é, [...] transparente: se os empresários souberam triunfar na vida isto é, se souberam desenvolver-se com êxito, no mercado - e o que está faltando, em nossas escolas, é justamente competição, [...]. O sistema educacional deve converter-se, ele mesmo, num mercado. Assim, devem ser consultados aqueles que melhor entendem do mercado, para nos ajudarem a sair da improdutividade e da ineficiência que caracteriza as práticas escolares e que regulam a lógica cotidiana das instituições educacionais, em todos os níveis. (GENTILI, 2014, p. 25).

Na contramão desse raciocínio, é dever da escola formar pessoas aptas a lutarem por seus direitos como forma de enfrentamento à exclusão social impulsionada pelos avanços científicos e tecnológicos, novos processos de produção, novas formas de conhecimento e ação que também provocaram o distanciamento socioeconômica entre incluídos e excluídos desse processo.

Por certo, a escola contemporânea assume dois papéis: voltar-se para as novas realidades vinculadas ao mundo econômico, político, cultural, e lutar contra a exclusão social em busca de um projeto de sociedade mais justa. A escola deve perpassar uma formação que sintetize cultura formal (dos conhecimentos sistematizados) com cultura experienciada no cotidiano popular, bem como o domínio de linguagens.

A escola não pode se desviar da formação que articule recebimento e interpretação da informação a partir de estudantes capazes de se reconhecerem como sujeitos de direitos, sobretudo quando os conhecimentos produzidos fora dos muros da escola sejam respeitados e associados à educação formal. Nessa perspectiva, o reconhecimento do saber popular seria o caminho para o empoderamento resultante da palavra como exercício do saber coletivo, e, consequentemente, o exercício de seu poder, demanda que atravessa a educação popular.

\section{Algumas Considerações}

A Educação Popular tem sua origem nos movimentos e nas organizações de base, ela acontece fora dos muros da escola, seus princípios e sua metodologia atravessavam práticas emancipatórias, repercutindo de modo positivo na sociedade que percebe o quão é necessário sua presença nos espaços educativos, inclusive cruzando as fronteiras e os muros das escolas, sobretudo na contribuição que suas práticas educativas podem oferecer.

\begin{tabular}{|l|l|l|l|l|}
\hline Qenista Dialectus & Ano 10 & n. 24 & Setembro - Dezembro 2021 & p. 233 - 247 \\
\hline
\end{tabular}


Sua presença, hoje, nos espaços escolares e educativos dos sindicatos, ONGs, Associações de Moradores, conselhos populares entre outros é uma realidade construída, mas marcada por constantes ameaças de governos autoritários que não visam a formação política do povo. São grandes os desafios de quem partilha dos saberes oriundos da Educação popular uma vez que ela conduz a ação humana às relações de poder que perpassam um campo de disputas em que força e poder parecem comungar do mesmo significado.

Atualmente, no Brasil, os detentores das decisões que convergem com os interesses do neoliberalismo vem travando uma cruzada, atuando de modo perverso, contra os representantes da educação popular e seus espaços. Paulo Freire passou a ser uma espécie de inimigo da nação por sempre lutar por propor uma educação para todas, sobretudo conscientizadora, capaz de compreender a realidade e de nossa ação no mundo, uma educação política.

A educação popular corresponde à uma para práxis que transforme a realidade social, ela propõe um novo projeto de sociedade pautada na justiça social com participação popular. Nela, o processo educativo se constitui na ação que visa mudança na realidade social, nosso processo educativo deve nos conduzir à realidade social para transformá-la quando presenciamos injustiça e exclusão social.

\section{Referências}

ARAÚJO, Raquel Dias. Capitalismo, Estado e Educação: primeiras aproximações. In: AYRES, Natália et al. Pedagogia e psicologia Marxista: a revolução teórica no interior da revolução social. 1. ed. Curitiba: Editora Prismas, 2016, p. 321-335.

ARAÚJO, Raquel Dias; AYRES, Natália; Eduardo Ferreira Chagas. Estado, Educação e Planejamento Educacional: entrelaçamentos teórico-práticos. Revista Dialectus - Revista de Filosofía da UFC- Fortaleza, Fortaleza, Ano 9, n. 16, p. 100 - 112, janeiro-abril, 2020.

BOURDIEU, Pierre. Escritos de Educação. Maria Alice Nogueira e Afrânio Mendes Catani (Organizadores). 16. ed. Petrópolis - RJ: Vozes, 2015, p. 7-16/45-88.

BRANDÃO, Carlos Rodrigues. Educação Popular (O que é educação popular). 3. ed. São Paulo: Brasiliense, 1986.

FOUCAULT, Michel. Microfísica do poder. Organização e tradução de Roberto Machado. 4.ed. Rio de Janeiro: Edições Graal, 1984. 
GENTILI, Pablo. O Consenso de Washington e a crise da educação na América Latina. In: $A$ falsificação do consenso: simulacro e imposição na reforma educacional do neoliberalismo. Petropólis - RJ: Vozes, 1998.

LIBÂNEO, José Carlos. As reformas educacionais e os planos de educação. In: Educação escolar: políticas, estrutura e organização. 10 ed. revisada e ampliada. São Paulo: Cortez, 2012

SAVIANI, Dermeval. Política educacional brasileira: limites e perspectivas. Revista de Educação PUC - Campinas, Campinas, n. 24, p. 7-16, junho de 2008. 